\title{
Hepatitis B virus associated membranous glomerulonephritis
}

\author{
J WIGGELINKHUIZEN, C SINCLAIR-SMITH, L M STANNARD, AND H SMUTS \\ Department of Paediatrics, Department of Pathology, and Department of Medical Microbiology, \\ University of Cape Town, and Red Cross War Memorial Children's Hospital, Cape Town, South Africa
}

SUMMARY The incidence of persistent hepatitis B surface (HBs) antigenaemia was studied in 114 nephrotic children with glomerulonephritis. Twenty five ( 24 boys) of 28 cases of membranous glomerulonephritis were $\mathrm{HBs}$ antigen $(\mathrm{HBsAg})$ carriers. Only 9 of the remaining 86 patients with nephropathies other than membranous glomerulonephritis were $\mathrm{HBs} A g$ positive. HBsAg immune complexes were seen in the sera by electron microscopy. On radioimmunoassay both $\mathrm{HBsAg}$ and antibody (anti-HBs), and $\mathrm{HBeAg}$ and antibody (anti-HBe) were often detected concurrently. HBsAg was not shown in the glomerular capillary wall. HBs antigenaemia persisted in $80 \%$ of patients after recovery from glomerulonephritis but remission of the proteinuria correlated well, although not fully, with seroconversion to anti-HBe. The natural history of hepatitis B virus (HBV) associated glomerulonephritis in childhood is one of slow recovery. A few patients are left with mild asymptomatic proteinuria but progressive renal failure is rare. The $14 \%$ incidence of membranous glomerulonephritis in nephrotic children in this area is much higher than that found by the international study of kidney disease in children in well developed countries and is probably related to a high HBV carrier rate. A search for HBV markers should be included in the investigation of persistent glomerulonephritis, particularly in countries with a high prevalence of HBV carriers.

Hepatitis B virus (HBV) infection has been implicated in several extrahepatic disorders most of which are mediated by immune complexes. ${ }^{12}$ Glomerulonephritis associated with HBV infection was first described by Combes et al., ${ }^{3}$ who showed Australia antigen antibody complexes in the glomerular basement membrane of an adult with membranous glomerulonephritis (MGN) after post-transfusion hepatitis. Since then several case reports ${ }^{4-10}$ and the results of studies of a few small series ${ }^{11-14}$ have been published that link HBV infection with immune complex induced glomerulonephritis. Although most authors have implicated hepatitis B surface antigen (HBsAg) immune complexes as a cause of glomerulonephritis, Takekoshi et al..$^{15}$ and Ito et al..$^{16}$ have recently shown that this disease may be mediated by hepatitis $\mathrm{Be}$ antigen $(\mathrm{HBeAg})$ complexes. We report on a study of 34 children with glomerulonephritis and nephrotic syndrome who had persistent HBs antigenaemia.

\section{Patients and methods}

Sera from 114 nephrotic children under 13 years of age ( 80 boys and 34 girls) were screened for markers of $\mathrm{HBV}$ infection. All $\mathrm{HBs} \mathrm{Ag}$ positive children were followed up regularly for 4 months to $9 \frac{1}{2}$ years. Three patients were lost to follow up 4, 15, and 16 months after the onset of nephrotic syndrome and 3 have been followed for less than 12 months. A further 71 children ( 49 boys and 22 girls) were first screened for HBsAg only after complete remission of their renal disease.

Nephrotic syndrome was defined as massive proteinuria $>1 \mathrm{~g} / \mathrm{m}^{2} /$ day with consequent hypoalbuminaemia of $25 \mathrm{~g} / \mathrm{l}$ or less; moderate persistent proteinuria was defined as 2 to $3+$ proteinuria measured semiquantitatively by Albustix, with a plasma albumin of 26-34 $\mathrm{g} / \mathrm{l}$; and mild asymptomatic proteinuria defined as $1+$ on semiquantitative testing, with a plasma albumin of $>35 \mathrm{~g} / \mathrm{l}$.

One HBsAg positive patient aged 3 years at the time of the study had had congenital syphilis with glomerulonephritis as a neonate but had made a rapid and full recovery. None of the other HBV carriers had a history or signs of systemic disease or exposure to toxic substances known to induce renal disease and none had received blood transfusions or other blood products. 
Laboratory investigations included routine renal function tests, plasma protein and cholesterol concentrations, venereal disease research laboratory test (VDRL), lupus erythematosus cell preparations or the Crithidia test, anti-DNA antibodies, antinuclear factor, throat culture and antistreptolysin-0 titre, total serum complement, and $\mathrm{C}_{3}$ and $\mathrm{C}_{4}$ fractions. Serum alanine aminotransferase, bilirubin, alkaline phosphatase, $\alpha$ fetoprotein values, and smooth muscle and mitochondrial antibody titres were measured at intervals in most patients.

Screening of sera for HBV markers. Before 1976, HBsAg was detected by passive haemagglutination, but since then radioimmunoassays (RIA) have been used to detect HBsAg and antibody (Ausria II and Ausab, Abbott Laboratories) and $\mathrm{HBeAg}$ and antibody (Abbott-HBe). The tests were repeated at intervals in all the HBsAg positive patients except 1 (case 18) who was lost to follow up. Serum samples from 5 patients were centrifuged at $50000 \mathrm{~g}$ for 1 hour and the sediments were examined for immune complexes by negative staining electron microscopy using $2 \%$ phosphotungstic acid (pH $6 \cdot 1)$.

Histological examination. Biopsy specimens of kidney tissue taken by percutaneous needle were immediately divided into 3 parts; 1 part was fixed in Bouin's fluid, a second in $4 \%$ s-collidine buffered glutaraldehyde, and a third snap frozen in liquid nitrogen. Sections for light microscopy were stained with haematoxylin and eosin, periodic acid Schiff, Masson's trichrome, and methenamine silver.

Material for ultrastructural examination was postfixed in osmium tetroxide and embedded in Spurr's resin. Sections were stained with uranyl acetate and lead citrate and examined with a Philips 201 electron microscope. Frozen sections cut at $4 \mu \mathrm{m}$ were stained by a direct immunofluorescence technique using commercially obtained fluorescein isothiocyanate labelled anti-IgG, anti-IgA, anti-IgM, antifibrin, anti-C3, and anti-C1q and anti-C4 antisera (Behringwerke AG Marburg, West Germany).

Biopsy sections from 22 cases of HBV associated MGN were embedded in paraffin wax and examined for HBsAg using the indirect peroxidase antiperoxidase method. Commercially prepared (Behringwerke AG) rabbit anti-HBs was used as the primary antiserum at a dilution of 1:15. Swine anti-rabbit serum and the peroxidase antiperoxidase complex were supplied by Dakopatts, Copenhagen, Denmark. The reaction sites were shown by 3 , 3-diaminobenzidine tetrahydrochloride at a $\mathrm{pH}$ of $7 \cdot 6$.

\section{Results}

Thirty four of the 114 patients with active renal disease were HBsAg carriers (Table 1). Seven of the $34 \mathrm{HBs} A g$ positive patients were excluded from the group diagnosed as having $\mathrm{HBV}$ associated glomerulonephritis: 5 had steroid responsive minimal change nephropathy (biopsy proved in 2 cases or presumed in 3 cases), 1 had anaphylactoid purpura glomerulonephritis (biopsy not done), and 1 had acute poststreptococcal glomerulonephritis. The course of disease in these 7 patients did not seem to be related to HBs antigenaemia as the first 5 patients relapsed and the remaining 2 recovered rapidly.

Two HBsAg carriers had mesangial proliferative glomerulonephritis and the remaining 25 patients with persistent HBs antigenaemia had membranous

Table 1 Renal histopathology and hepatitis B surface antigen (HBsAg) radioimmunoassay (RIA) in children with, or in remission from, glomerulonephritis

\begin{tabular}{|c|c|c|c|c|c|c|c|}
\hline & \multicolumn{3}{|c|}{$\begin{array}{l}\text { HBsAg } R I A \text { at onset of } \\
\text { renal disease }\end{array}$} & \multicolumn{3}{|c|}{$\begin{array}{l}\text { HBsAg RIA first done after remission } \\
\text { of renal disease }\end{array}$} & \multirow[t]{2}{*}{$\begin{array}{l}\text { Total No cases } \\
\text { screened }\end{array}$} \\
\hline & No positive & No negative & Total No & No positive & No negative & Total No & \\
\hline 'Minimal change' nephropathy & 2 & 12 & 14 & 1 & 10 & 11 & 25 \\
\hline Focal segmental glomerulosclerosis & - & 4 & 4 & - & 1 & 1 & 5 \\
\hline Diffuse proliferative GN & 1 (AGN) & 5 & 6 & 2 & 4 & 6 & 12 \\
\hline Mesangial proliferative GN & 2 & 17 & 19 & 4 & 13 & 17 & 36 \\
\hline Focal proliferative GN & 二 & - & - & 1 & 1 & 2 & 2 \\
\hline Crescentic GN & 一 & 3 & 3 & - & 2 & 2 & 5 \\
\hline Membranoproliferative GN & - & 4 & 4 & - & 二 & 二 & 4 \\
\hline Membranous GN & 25 & 3 & 28 & 6 & 4 & 10 & 38 \\
\hline Miscellaneous diagnoses & - & 1 & 1 & - & 1 & 1 & 2 \\
\hline Biopsy not done & $4^{*}$ & 31 & 35 & 2 & 19 & 21 & 56 \\
\hline Total No & 34 & 80 & 114 & 16 & 55 & 71 & 185 \\
\hline
\end{tabular}

GN = glomerulonephritis. AGN = post-streptococcal acute glomerulonephritis.

*Three patients had steroid responsive nephropathy and 1 had anaphylactoid purpura. 


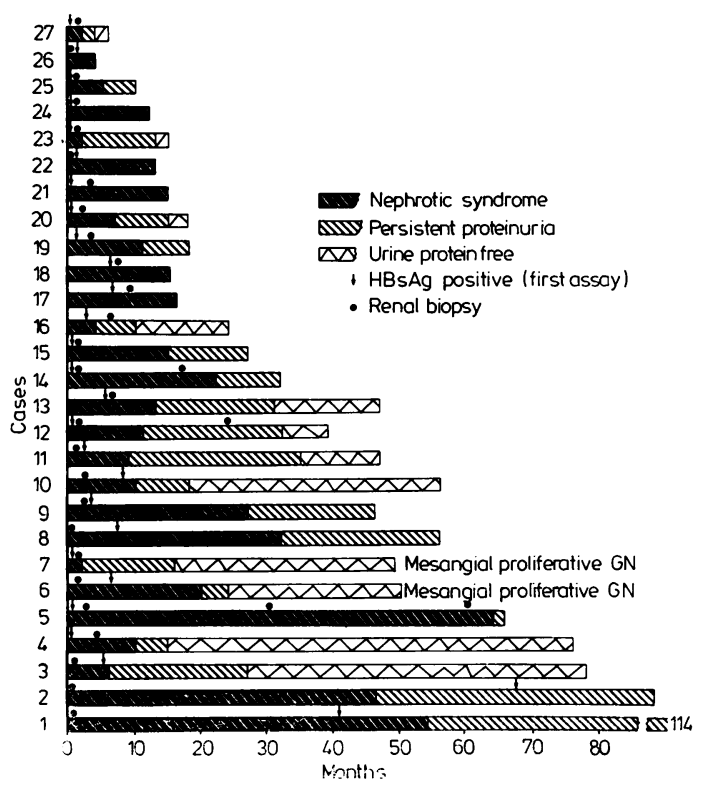

Fig. 1 Course of hepatitis $B$ virus associated glomerulonephritis.

glomerulonephritis (MGN) (Fig. 1). The MGN group, who form the main substance of this report comprised 24 boys and 1 girl, with an average age of 6 years (range 2-12 years, median $6 \frac{1}{2}$ years). Seventeen children were of mixed ethnic extraction and 8 were black. Although about $15 \%$ of nephrotic children seen at this clinic are Caucasian, none of those screened were HBsAg carriers or had MGN. In most cases the first assay for $\mathrm{HBsAg}$ was done within 6 months of the clinical onset of MGN. The timing of the first HBsAg assay and the taking of a renal biopsy specimen are shown in Fig. 1. Follow up periods varied from 4 months to more than 9 years with an average of 37 months (median 27 months) (Fig. 1).

All patients with $\mathrm{HBV}$ associated MGN presented with oedema of varying severity and heavy proteinuria; 13 had macrohaematuria, while a further 6 patients had microscopic haematuria. Three patients had transient mild hypertension. No patient was jaundiced, ascites was present in 15 patients, 9 had hepatomegaly, and 4 had hepatosplenomegaly.

Urinary protein excretion ranged from 1.0 to 8.1 $\mathrm{g} / 24$ hours (average $2.9 \mathrm{~g} / 24$ hours, median 2.3 $\mathrm{g} / 24$ hours) and was highly selective in 6 of the 10 patients where this was assessed. Serum protein electrophoresis showed the nephrotic pattern and average concentrations of serum albumin
$17.04 \mathrm{~g} / \mathrm{l}$, alpha-1-globulin $2.64 \mathrm{~g} / \mathrm{l}$, apha-2-globulin $14.3 \mathrm{~g} / \mathrm{l}$, beta globulin $7 \cdot 3 \mathrm{~g} / \mathrm{l}$ and gammaglobulin $7 \cdot 3 \mathrm{~g} / \mathrm{l}$. Mean values of immunoglobulin $\mathrm{G}, \mathrm{A}$, and $M$ in 18 patients were in the normal range. Five patients had transient raised blood urea values of $>7 \mathrm{mmol} / \mathrm{l}(>40 \mathrm{mg} / 100 \mathrm{ml})$ because of prerenal failure; plasma creatinine concentrations were normal. Plasma cholesterol concentrations ranged from 4.0 to $23.6 \mathrm{mmol} / 1(154-908 \mathrm{mg} / 100 \mathrm{ml})$, mean $9.6 \mathrm{mmol} / \mathrm{l}(369 \mathrm{mg} / 100 \mathrm{ml})$.

Nineteen patients including 7 with hepatomegaly and 3 with hepatosplenomegaly, had raised serum alanine aminotransferase values (43-285 U/1) on 1 or more occasions during the course of the renal disease. In 6 patients the concentration exceeded $100 \mathrm{U} / 1$ and a liver biopsy specimen taken from 4 of these patients showed mild chronic active or persistent hepatitis. Lupus erythematosus cell preparations or the Crithidia test, or both, were negative in all patients. The results of other laboratory investigations are given in Table 2. The HBsAg status of patients first screened after remission of the nephrotic syndrome is also given in Table 1 . Six of 10 MGN patients who were screened 1 to 10 years after complete recovery were $\mathrm{HBsAg}$ positive.

\section{Histopathology}

HBV associated MGN was found in various stages of severity and healing and, although not uniform in all glomeruli in the same biopsy specimen, the predominant histological stage was $I$ in 3 patients, II in 15 , III in 5 , and IV in 2 patients. ${ }^{17}$ There was no correlation between the stage of MGN and the

Table 2 Laboratory investigations in hepatitis $B$ virus associated membranous glomerulonephritis

\begin{tabular}{|c|c|c|c|}
\hline & No & $\begin{array}{l}\text { No of patients } \\
\text { tested }\end{array}$ & Normal range \\
\hline $\begin{array}{c}\beta \text {-haemolytic Streptococci } \\
\text { on throat swab culture }\end{array}$ & 5 & 18 & \\
\hline $\begin{array}{l}\text { Antistreptolysin } 0 \text { titre } \\
>200 \text { IU }\end{array}$ & 5 & 23 & \\
\hline $\begin{array}{l}\text { Complement total } \\
\text { decreased }\end{array}$ & 13 & 25 & $160-220 \mathrm{U} / \mathrm{ml}$ \\
\hline $\begin{array}{l}\text { C3 decreased } \\
\text { C4 decreased }\end{array}$ & $\begin{array}{r}12 \\
1\end{array}$ & $\begin{array}{r}16 \\
9\end{array}$ & $\begin{array}{l}115-150 \mathrm{mg} / 100 \mathrm{ml} \\
15-45 \mathrm{mg} / 100 \mathrm{ml}\end{array}$ \\
\hline $\begin{array}{l}\text { VDRL or fluorescent } \\
\text { Treponema absorption } \\
\text { test, or both, negative }\end{array}$ & 23 & 23 & \\
\hline $\begin{array}{l}\text { Antinuclear factor positive } \\
\text { titres } 1: 10,1: 20\end{array}$ & 2 & 21 & \\
\hline $\begin{array}{l}\text { Anti-DNA antibodies } \\
>5 \mu \mathrm{g} \text { bound } / \mathrm{ml} \text { serum } \\
\text { (range } 6-18 \text { ) }\end{array}$ & 9 & 14 & normal $₹ 5 \mu \mathrm{g} / \mathrm{ml}$ \\
\hline $\begin{array}{l}\text { Mitochondrial antibodies } \\
\text { absent }\end{array}$ & 14 & 14 & \\
\hline $\begin{array}{l}\text { Smooth muscle antibodies } \\
\text { present in titres } 1: 10 \\
\text { to } 1: 40\end{array}$ & 6 & 14 & \\
\hline
\end{tabular}


interval between clinical onset and the time the biopsy specimen was taken or remission. Mild mesangial cell proliferation with an increase in mesangial matrix and mild polymorphonuclear leucocyte exudation was frequent in the earlier stages but less obvious later.

Electron microscopy showed that immune complex deposition ranged from relatively few subepithelial aggregates affecting some loops only to marked subepithelial deposition and incorporation of the deposits into the thickened glomerular basement membrane. In the later stages massive thickening of the basement membrane and at times striking interposition of mesangial cytoplasm and matrix between the basement membrane and endothelium of the glomerular capillary loop was seen (Fig. 2).

Immunofluorescence studies showed striking granular deposition of IgG and to a lesser extent C3 and IgM in the capillary loops and less so in the mesangium. Peroxidase antiperoxidase staining for HBs antigen was negative.

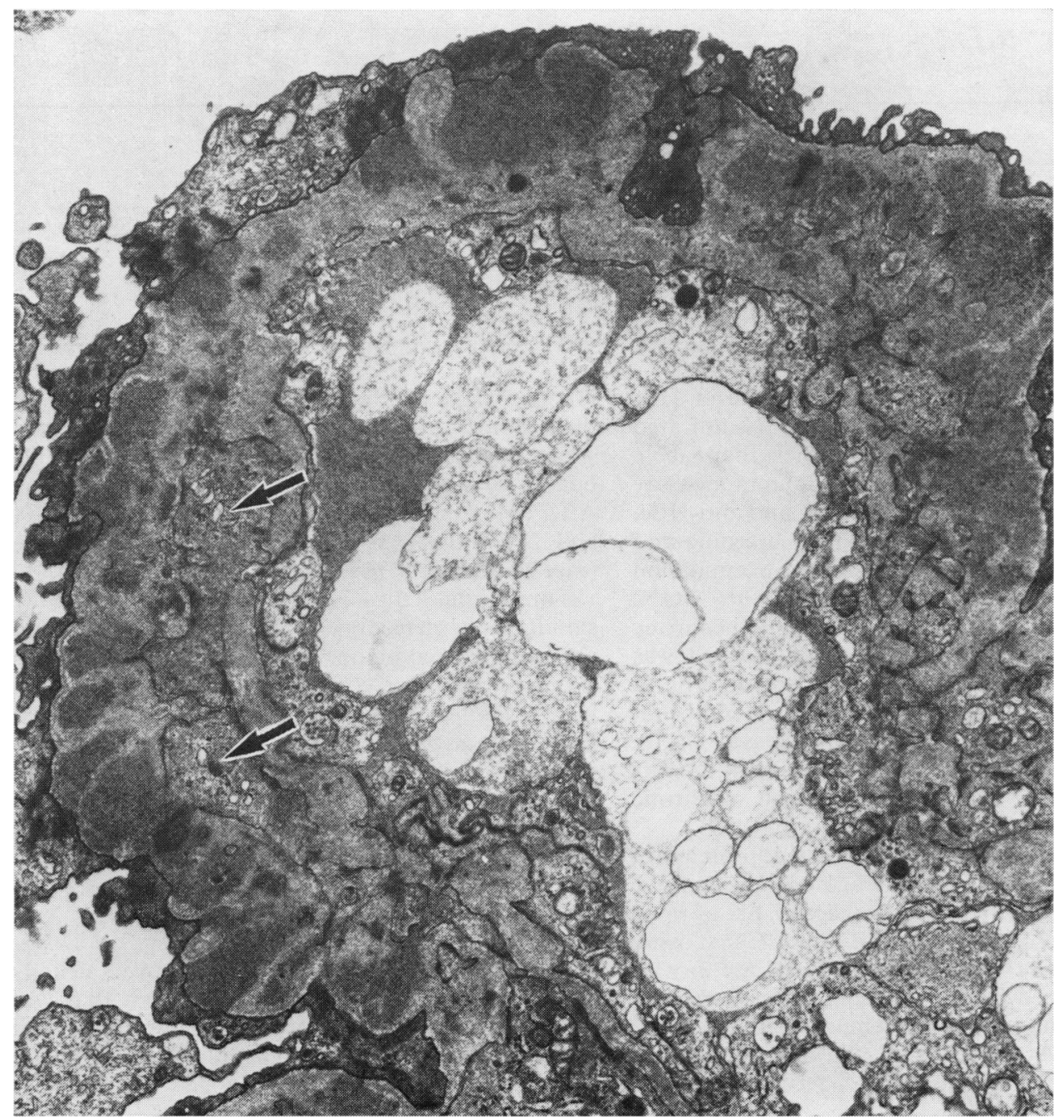

Fig. 2 Electron micrograph $(\times 16320)$ of glomerular capillary loop showing many subepithelial electron dense deposits some of which are being incorporated into the thickened basement membrane. Note the interposition of mesangial cytoplasm (arrow) and fusion of the footprocesses. Late membranous glomerulonephritis. 
Table 3 Hepatitis B virus markers in hepatitis B virus associated membranous glomerulonephritis

\begin{tabular}{|c|c|c|c|c|c|c|c|c|}
\hline \multirow[t]{2}{*}{ Case No } & \multicolumn{4}{|c|}{ First assay } & \multicolumn{4}{|c|}{ Latest assay } \\
\hline & $H B s A g$ & anti-HBs & $\mathrm{HBeAg}$ & anti-HBe & $H B s A g$ & anti-HBs & $\mathrm{HBeAg}$ & anti-HBe \\
\hline 17 & + & & & & \multicolumn{4}{|c|}{ Continuing nephrotic syndrome } \\
\hline 18 & + & & & & & & & \\
\hline 21 & + & + & + & - & + & + & + & - \\
\hline 22 & + & - & + & - & + & - & + & - \\
\hline 24 & + & - & + & - & + & - & + & - \\
\hline \multirow[t]{2}{*}{26} & + & - & + & - & + & - & + & - \\
\hline & & & & & \multicolumn{4}{|c|}{ Persistent proteinuria } \\
\hline 1 & + & - & & & + & - & - & + \\
\hline 2 & + & - & - & + & + & - & - & + \\
\hline 5 & + & - & + & + & + & - & - & + \\
\hline 8 & + & + & & & + & + & - & + \\
\hline 9 & + & & & & - & + & - & + \\
\hline 14 & + & - & + & + & + & - & + & - \\
\hline 15 & + & - & + & - & + & - & + & - \\
\hline 19 & + & - & + & + & + & - & + & + \\
\hline \multirow[t]{2}{*}{25} & + & - & + & - & + & - & + & - \\
\hline & & & & & \multicolumn{4}{|c|}{ Remission } \\
\hline 3 & + & - & & & + & - & - & + \\
\hline 4 & + & - & & & - & + & - & + \\
\hline 10 & + & - & & & + & - & - & + \\
\hline 11 & + & - & + & - & + & - & + & - \\
\hline 12 & + & & & & - & + & - & + \\
\hline 13 & + & + & & & + & - & - & + \\
\hline 16 & + & + & + & + & + & + & - & + \\
\hline 20 & + & - & + & - & + & + & + & + \\
\hline 23 & + & - & + & - & + & - & - & + \\
\hline 27 & + & - & + & - & + & - & + & - \\
\hline
\end{tabular}

HBV marker status. Prolonged persistence of HBs antigenaemia in all 25 patients with MGN indicated the asymptomatic carrier state rather than acute infection. Table 3 shows the radioimmunoassay results for $\mathrm{HBsAg}$, anti-HBs, $\mathrm{HBeAg}$, and anti-HBe. The HBV markers found at the first screening and after remission or at the latest follow up examination are given for each of the 25 patients with MGN. Five of the 6 patients with continuing nephrotic syndrome remained $\mathrm{HBs} \mathrm{Ag}$ positive (case 18 was screened only once) and all 4 screened for $\mathrm{HBeAg}$ were positive throughout the follow up period that averaged 12 months. The 3 children (cases 17, 18, and 26) lost to follow up 16, 15, and 4 months respectively after onset all had florid nephrotic syndrome when last seen.

Of the 9 MGN patients with persistent proteinuria who were followed for an average of 51 months, 1 seroconverted fully to anti-HBs (case 9). Six of these 9 patients were screened for $\mathrm{HBeAg}$ at the first assay and all were $\mathrm{HBeAg}$ positive except 1 (case 2) who was first screened late in his renal disease when he had mild asymptomatic proteinuria and was antiHBe positive. At the latest assay 5 of the 9 patients with persistent proteinuria had seroconverted to anti-HBe.

Two only of the 10 MGN patients (cases 4 and 12) who went into remission during the study seroconverted to anti-HBs positive and 8 are persistent
HBsAg carriers, although they have recovered from their glomerulonephritis. In the early phase of the study $\mathrm{HBeAg}$ and anti-HBe assays were not available but all 5 patients screened were $\mathrm{HBeAg}$ positive. After remission 3 were $\mathrm{HBeAg}$ positive (cases 11, 20, and 27) while 8 patients were anti-HBe positive (case 20 was both $\mathrm{HBeAg}$ and anti-HBe positive).

Throughout the period of observation the simultaneous detection of $\mathrm{HBsAg}$ and $\mathrm{HBeAg}$ and antibody was common, showing the probability of circulating immune complexes. This condition often lasted for longer than a year and sometimes fluctuated between antigen positivity alone and concurrent detection of antigen and antibody until final seroconversion occurred. All of the 5 sera examined by negative staining electron microscopy contained large numbers of $\mathrm{HBsAg}$ immunc complexes (Fig. 3).

\section{Course}

The course of the renal disease improved steadily (Fig. 1), with fluctuating oedema at first that was often associated with intercurrent infection. Ten patients gradually went into spontaneous remission after intervals ranging from 4 to 38 months. The average interval to full recovery was 20 months (median 16 months); no relapses have thus far occurred over an average follow up period of 40 months (median 43 months). 


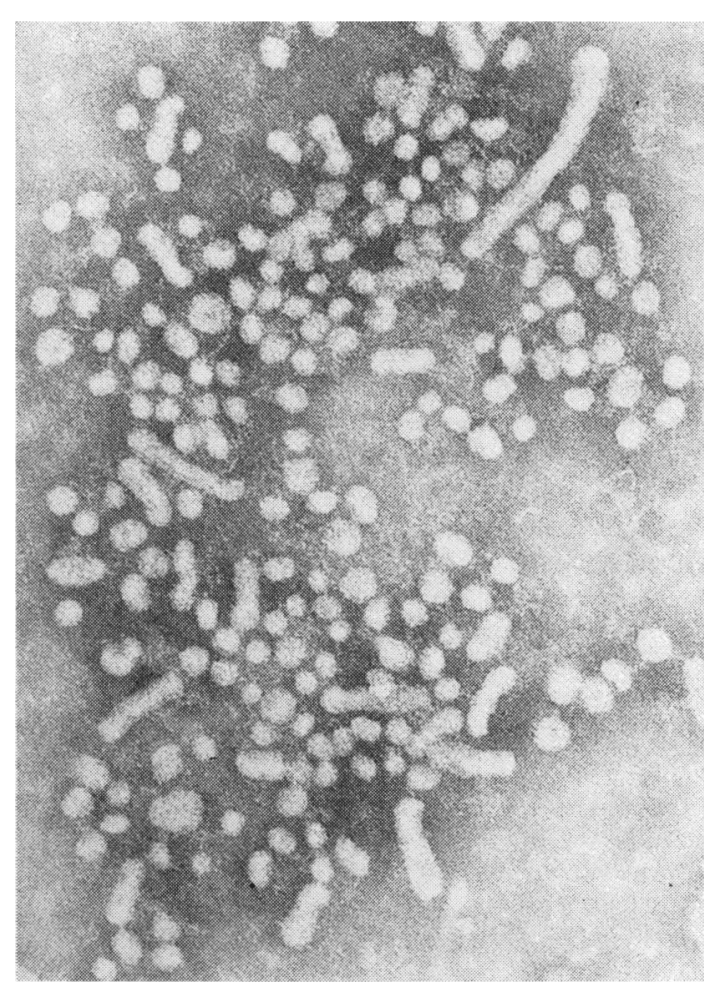

Fig. 3 Electron micrograph $(\times 120000)$ of an immune complex of spherical and filamentous components of hepatitis $B$ surface antigen seen in the serum of $a$ patient with active membranous glomerulonephritis. Linking antibody molecules are visible between the particles.

Six patients still had nephrotic syndrome when last seen after follow up periods of 4-16 months (average 12 months): the condition of 3 patients who still had nephrotic syndrome when lost to follow up is, however, unknown. Only 1 patient (case 5) followed for more than 5 years has mild impairment of renal function and hypertension and persistent proteinuria and haematuria. Two repeat biopsy specimens taken from this child 30 and 60 months after the first showed increased thickening of the glomerular basement membrane, with subepithelial and intramembranous immune complex deposition, and appreciable interposition of mesangial cytoplasm and matrix beneath the endothelium.

Five patients (cases 5, 9, 14, 19, and 25) have moderate persistent proteinuria-2 with microscopic haematuria-and are mildly symptomatic at times. The average duration of follow up in this subgroup was 34 months. Four asymptomatic patients (cases
$1,2,8$, and 15 ) have mild residual proteinuria only and normal blood biochemistry after follow up periods ranging from 27 months to more than 9 years (average 71 months).

Macrohaematuria rarely lasted more than a few weeks, although 2 patients had transient recurrent macrohaematuria in the first year. At the last follow up all but 1 of the children with continuing nephrotic syndrome still had microscopic haematuria. No patient has had symptomatic liver disease. Seven children still had serum alanine aminotransferase values $>40 \mathrm{U} / 1$ at the last follow up and none of these were in remission. The clinical course of 2 HBsAg carriers with mesangial proliferative glomerulonephritis was similar to that of the children with MGN. Both were in remission 16 and 24 months after the clinical onset of their renal disease (included in Fig. 1).

\section{Discussion}

HBV infection is known to be associated with extrahepatic clinical manifestations thought to be immune complex mediated such as polyarteritis nodosa. Much evidence now exists implicating HBV antigen as a cause of immune complex induced glomerulonephritis. Under experimental conditions and in naturally occurring viral infections in animals immune complex mediated glomerulonephritis requires a continuous excess supply of antigen and a maintained but limited antibody response. The inadequate antibody response cannot eliminate the viral antigen and halt the infection, although it can form nephritogenic immune complexes. ${ }^{18} 19$ Such conditions may prevail in HBV infection where large amounts of viral antigenic material are produced in the hepatocytes, for prolonged periods in the carrier state, and released into the circulation. Varying levels of immune response are stimulated that in some instances not only permit the carrier state to persist but also favour the production of complexes capable of mediating glomerulonephritis. Circulating immune complexes of $\mathrm{HBsAg}^{20} 21$ and $\mathrm{HBeAg}{ }^{22}$ have been found in hepatitis $B$ positive serum.

The correlation between HBs antigenaemia and MGN is striking $-89 \%$ of the children with active MGN were HBsAg carriers (Table 1). Two of the other 3 patients had idiopathic MGN (1 anti-HBs positive) and 1 had systemic lupus erythematosus. The association is further supported by the finding of HBsAg in the sera of 6 of the 10 children who had recovered from MGN (Table 1). In these children HBsAg negative sera were not screened for anti-HBs and so seroconverted cases would not have been detected. 
The incidence of MGN in a total of 331 cases of nephrotic syndrome that we have seen over 13 years is $14.2 \%$-much higher than that found by the international study of kidney disease in children in developed countries. ${ }^{23} \mathrm{HBV}$ associated renal disease seems responsible for this higher incidence of MGN in our childhood population. The striking male predominance is as yet unexplained.

The association between HBV infection and mesangial proliferative glomerulonephritis is more tenuous and may be incidental, although the clinical findings and course of the disease did not differ from HBV associated MGN (Fig. 1). Mesangial proliferation, often with mild exudation, was prominent in early MGN but not in advanced healing MGN and mesangial hypercellularity may be an early response to $\mathrm{HBV}$ immune complex deposition.

The prevalence of $\mathrm{HBsAg}$ carriers varies from $0.1 \%$ in parts of Europe, North America, and Australia to $15 \%$ or more in Asia and several tropical countries. ${ }^{24} 25$ In countries with a high prevalence of HBV carriers there may be a higher incidence of HBV associated glomerulonephritis. Vos et al. ${ }^{26}$ found an HBsAg carrier rate of $20.3 \%$ among South African blacks with unspecified renal disease compared with $9.8 \%$ in healthy voluntary black blood donors and concluded that HBsAg carriers were predisposed to renal disease. Nagy et al. ${ }^{27}$ detected HBs antigenaemia in $16.3 \%$ of Polish patients with immune complex glomerulonephritis. Excluding the cases of MGN, the incidence of HBs antigenaemia in this series of various glomerulonephritis is $10.5 \%$ in those with active renal disease and $16.4 \%$ in those with a past history of nephrotic syndrome, and this probably reflects the unknown carrier rate in the local children. Our own observations and published reports ${ }^{11-14}$ indicate that HBV associated glomerulonephritis is more common in children than in adults.

Takekoshi ${ }^{12}$ found a high incidence of HBV carriers and anti-HBs positivity among the mothers of children with $\mathrm{HBV}$ associated glomerulonephritis. $\mathrm{He}$ and others ${ }^{25}$ have suggested that perinatal vertical transmission from carrier mothers to their offspring is responsible for the high carrier rate in childhood.

Most of the patients in published reports of HBV associated renal disease have had MGN, $35610-16$ but mesangial proliferative, ${ }^{914}$ membranoproliferative glomerulonephritis, ${ }^{4} 711$ focal glomerulosclerosis, and endocapillary glomerulonephritis have also been reported. ${ }^{11}$ Late HBV associated glomerulonephritis may resemble membranoproliferative glomerulonephritis examination by light microscopy and this may lead to a wrong diagnosis if electron microscopy is not done.
How immune complexes are deposited in subepithelial sites in the glomerulus is still unclear. They may form 'in situ' by the deposition of alternate layers of antigen and antibody, or they may result from the 'lodging' of preformed circulating complexes. In this study $\mathrm{HBsAg}$ and immune complexes were seen in large numbers in all 5 sera examined by electron microscopy. These complexes varied in size and it is uncertain whether many of them would have been small enough to cross the undamaged glomerular basement membrane. Their role in the pathogenesis of glomerulonephritis is uncertain. The existence of circulating HBsAg immune complexes does, however, indicate the simultaneous presence of antigen and antibody in the serum, a feature often found also on radioimmunoassay. Similarly, radioimmunoassay often showed the simultaneous presence of $\mathrm{HBeAg}$ and antiHBe.

The molecular weight of $\mathrm{HBeAg}$ is approximately 30000 daltons, much less than $\mathrm{HBsAg}^{28}$ and well within the size capable of inducing immunecomplex glomerulonephritis. Ito et al..$^{16}$ have postulated that $\mathrm{HBeAg}$ may be the antigen in the pathogenesis of this immune complex induced glomerulonephritis, although another as yet undescribed HBV antigen cannot be excluded.

We could not show HBsAg in the deposits in the glomerulus. This negative finding has also been reported by other authors. ${ }^{13-15} 29$ Takekoshi et al..$^{15}$ could not detect $\mathrm{HBsAg}$ but showed $\mathrm{HBeAg}$, IgG, and $\beta 1 \mathrm{c}$ globulin along the glomerular basement membrane in 2 cases of MGN, and in their sera a small free $\mathrm{HBeAg}$, as well as a large form with $\mathrm{HBeAg}$ activity and IgG, and suggested that the latter is an HBeAg antibody complex. In 4 children with MGN and $\mathrm{HBsAg}$ and $\mathrm{HBeAg}$ in their sera, Ito et al. ${ }^{16}$ showed $\mathrm{HBeAg}$ as well as IgG, IgM, and $\beta 1 \mathrm{c}$ globulin in the glomeruli of all 4, but HBsAg in only 1 patient, in whom they postulated that HBsAg had been deposited secondary to glomerular basement membrane damage induced by $\mathrm{HBeAg}$ and antibody complexes. Two further patients who were in remission and anti-HBe positive had no detectable $\mathrm{HBeAg}$ in their glomeruli. IgM antiglobulin activity located in IgM deposits (IgM anti-IgG fractions) may lead to erroneous positive HBsAg on immunofluorescence studies. ${ }^{29}$

In this study remission of the renal disease did not correlate with seroconversion to anti-HBs: the HBsAg carrier state has persisted in most patients who have fully recovered. On the other hand, most but not all children in remission or with mild asymptomatic proteinuria have seroconverted to anti-HBe. In the few who have not fully seroconverted the ratio of antigen to antibody may no 
longer be conducive to the production of nephritogenic immune complexes. Seroconversion to anti$\mathrm{HBe}$ preceded the disappearance of the proteinuria and the delay was presumably due to the time taken for the lesion to heal. In a few patients permanent damage may lead to mild persistent proteinuria.

The clinical features of $\mathrm{HBV}$ associated glomerulonephritis are indistinguishable from many other forms of persistent glomerulonephritis. Half the patients were at first thought to have poststreptococcal glomerulonephritis but the proteinuria was severe and soon manifested with the nephrotic syndrome. Macrohaematuria lasted a few weeks only and most patients were asymptomatic within 1-2 years after onset. Only 1 child with persistent proteinuria and advanced MGN found in a repeat biopsy specimen has recently required long term antihypertensive treatment and his glomerular filtration rate (DTPA technetium ${ }^{99 \mathrm{~m}}$ ) has dropped to $62 \mathrm{ml} / \mathrm{min} / 1.73 \mathrm{~m}^{2}$.

In this series the liver disease was asymptomatic and serum alanine aminotransferase levels were never above $300 \mathrm{U} / 1$. A wide spectrum of associated liver disorders has been reported: chronic persistent $^{14}$ and chronic active hepatitis, ${ }^{4-6914}$ cirrhosis, ${ }^{614}$ and fulminant hepatitis. ${ }^{6}$

Mildly increased anti-DNA antibody binding was often seen at first but did not persist. Similarly, low complement fractions suggestive of immune complex induced renal disease returned to normal during the disease.

Corticosteroid treatment in 6 of our patients was ineffective and no other immunosuppressive treatment was given. Several patients in published reports ${ }^{13}$ were treated with corticosteroids or immunosuppressive drugs, or both, without effect, and this treatment may inadvertently delay seroconversion to anti-HBe status and remission of the renal disease. ${ }^{16}$ The response to symptomatic and supportive treatment with a protein supplemented low salt diet, diuretics, and intravenous human albumin infusions when necessary was generally good and few patients needed repeated admissions to hospital.

The natural history of HBV associated glomerulonephritis is one of slow resolution over several years. In Kleinknecht's series the average period of duration of the nephrotic syndrome was 5 months and the time to resolution of the proteinuria 18 months. ${ }^{13}$ In our larger series full recovery was slower (20 months) and only two thirds of the patients followed up for 3 years or longer were in remission. A few patients are left with mild asymptomatic proteinuria but progressive renal failure is rare.

Investigations into the cause of persistent glomerulonephritis should include a search for HBV markers, particularly in countries with a high prevalence of $\mathrm{HBV}$ carriers.

We thank Ms Di Blake and Jim Purvis for technical expertise; Mrs $\mathbf{H}$ Varkevisser for help with the computerised analysis; Mrs Vivien Eyles for secretarial help.

\section{References}

1 Gocke DJ. Extrahepatic manifestations of viral hepatitis. Am J Med Sci 1975; 270: 49-52.

2 Nowoslawski A, Krawczynski K, Nazarewicz T, Slusarczyk J. Immunopathological aspects of hepatitis type B. Am J Med Sci 1975;270: 229-39.

3 Combes B, Stastny P, Shorey J, et al. Glomerulonephritis with deposition of Australia antigen-antibody complexes in glomerular basement membrane. Lancet 1971 ; ii: 234-7.

4 Myers BD, Griffel B, Naveh D, Jankielowitz T, Klajman A. Membranoproliferative glomerulonephritis associated with persistent viral hepatitis. Am J Clin Pathol 1973; 60: 222-8.

5 Kohler PF, Cronin RE, Hammond WS, Olin D, Carr RI. Chronic membranous glomerulonephritis caused by hepatitis B antigen-antibody immune complexes. Ann Intern Med 1974; 81 : 448-51.

- Bajtai G, Ambrus M, Paál M, Nagy J, Deák G. Letter: Hepatitis-B antigenaemia associated with progressive cirrhosis and membranous glomerulonephritis. Lancet 1975; 1 : 102-3.

7 Hirschel BJ, Benusiglio LN, Favre $\mathrm{H}$ et al. Glomerulonephritis associated with hepatitis B. Report of a case and review of the literature. Clin Nephrol 1977; 8: 404-9.

8 Knecht GL, Chisari FV. Reversibility of hepatitis B virus-induced glomerulonephritis and chronic active hepatitis after spontaneous clearance of serum hepatitis B surface antigen. Gastroenterology 1978; 75: 1152-6.

- Stratta P, Gamussi G, Ragni R, Vercellone A. Letter: Hepatitis-B antigenaemia associated with active chronic hepatitis and mesangioproliferative glomerulonephritis. Lancet 1975; ii: 179.

10 Hirsch HZ, Ainsworth SK, DeBeukelaer M, Brissie RM, Hennigar GR. Membranous glomerulonephritis in a child asymptomatic for hepatitis B virus. Am J Clin Pathol $1981 ; 75$ : 597-602.

11 Brzosko WJ, Krawczynski K, Nazarewicz T, Morzycka M, Nowoslawski A. Glomerulonephritis associated with hepatitis-B surface antigen immune complexes in children. Lancet 1974 ; ii: 477-82.

12 Takekoshi Y, Tanaka M, Shida N, Satake Y, Saheki Y, Matsumoto S. Strong association between membranous nephropathy and hepatitis-B surface antigenaemia in Japanese children. Lancet 1978; ii: 1065-8.

13 Kleinknecht C, Levy M, Peix A, Broyer M, Courtecuisse V. Membranous glomerulonephritis and hepatitis B surface antigen in children. J Pediatr 1979; 95: 946-52.

14 Slusarczyk J, Michalak T, Nazarewicz-de Mezer T, Krawczynski K, Nowoslawski A. Membranous glomerulopathy associated with hepatitis B core antigen immune complexes in children. Am J Pathol 1980; 98: 29-39.

15 Takekoshi Y, Tanaka M, Miyakawa Y, Yoshizawa $H$, Takahashi K, Mayumi M. Free 'small' and IgGassociated 'large' hepatitis $B$ e antigen in the serum and glomerular capillary walls of two patients with membranous glomerulonephritis. $N$ Engl J Med 1979; 300: 814-9.

16 Ito $\mathrm{H}$, Hattori S, Matusda I, et al. Hepatitis B e antigenmediated membranous glomerulonephritis. Lab Invest $1981 ; 44: 214-20$. 
17 Ehrenreich T, Churg J. Pathology of membranous nephropathy. Pathology 1968; 3: 145-86.

18 Dixon FJ. The pathogenesis of glomerulonephritis. Am J Med 1968; 44: 493-8.

19 Oldstone MB, Dixon FJ. Immune complex disease in chronic viral infections. $J$ Exp Med 1971; 134: 32s-40s.

20 Stannard LM, Moodie J, Keen GA, Kipps A. Electron microscopic study of the distribution of Australia antigen in individual sera of 50 serologically positive blood donors and two patients with serum hepatitis. $J$ Clin Pathol 1973; 26: 209-16.

21 Madalinski K, Bragiel I. HbsAg immune complexes in the course of infection with hepatitis B virus. Clin Exp Immunol 1979; 36: 371-8.

22 Stannard LM, Lennon M, Hodgkiss M, Smuts, H. An electron microscopic demonstration of immune complexes of hepatitis B e-antigen using colloidal gold as a marker. J Med Virol 1982; 9: 165-75.

23 International Study of Kidney Disease in Children. Nephrotic syndrome in children: prediction of histopathology from clinical and laboratory characteristics at time of diagnosis. Kidney Int 1978; 13 : 159-65.

24 McCollum RW, Zuckerman AJ. Viral hepatitis: report on a WHO informal consultation. J Med Virol 1981; 8: 1-29.
25 Stevens CE, Beasley RP, Tsui J, Lee WC. Vertical transmission of hepatitis B antigen in Taiwan. $N$ Engl $\mathrm{J}$ Med 1975; 292: 771-4.

26 Vos GH, Grobbelaar BG, Milner LV. A possible relationship between persistent hepatitis B antigenaemia and renal disease in southern African Bantu. S Afr Med J 1973; 47: 911-2.

27 Nagy J, Bajtai G, Brasch $\mathrm{H}$, et al. The role of hepatitis $B$ surface antigen in the pathogenesis of glomerulonephritis. Clin Nephrol 1979;12: 109-16.

28 Tedder RS, Bull FG. Characterization of ' $\mathrm{e}$ ' antigen associated with hepatitis B. Clin Exp Immunol 1979; 35: 380-9.

29 Maggiore Q, Bartolomeo F, L'Abbate A, Misefari V. HBs Ag glomerular deposits in glomerulonephritis: fact or artifact? Kidney Int 1981 ; 19: 579-86.

Correspondence to Dr J Wiggelinkhuizen, Institute of Child Health, Red Cross War Memorial Children's Hospital, Rondebosch, Cape Town 7700, South Africa.

Received 8 February 1983

\section{Editorial note}

Subscribers will be glad to know that in this year of 1983, with a United Kingdom inflation rate of 7-8\%, the subscription to the Archives is being increased by only $5-6 \%$, and yet the number of pages is being increased by $12-13 \%$. This and future issues of the journal will be larger. 